\title{
The benefit of categorization in visual search: Target location without identification
}

\author{
JOHN JONIDES \\ University of Michigan, Ann Arbor, Michigan 48109 \\ and \\ HENRY GLEITMAN \\ University of Pennsylvania, Philadelphia, Pennsylvania 19104
}

\begin{abstract}
Prior studies have shown that between-category visual search (e.g., looking for a " 6 " among letters) is easier that within-category search (e.g., looking for a " 6 " among other digits). Four experiments were performed to determine what particular benefits are conferred in between-category search. The first experiment demonstrates that this category-effect occurs even when the subject has to identify the target; this suggests that the between-category search can "tag" the categorially different item for further processing. Three further experiments provide evidence that this tag is based on the item's spatial location within the array.
\end{abstract}

By now, there have been many demonstrations of a category effect in visual search when alphanumeric characters are used as target and field items. Target items are detected faster and more accurately in a between-category condition in which the field items are drawn from a different conceptual category (e.g., a "4" among letters) than they are in a within-category condition in which all array items belong to the same category (e.g., a " $B$ " among other letters). Thus, Brand (1971) and Ingling (1972) found that between-category search results in less time per item to detect the target in a variant of Neisser's (1963) scanning paradigm than does withincategory search.

Egeth, Jonides, and Wall (1972), Gleitman and Jonides (1976) and Jonides and Gleitman (1972), have demonstrated the same phenomenon by means of a somewhat different visual search technique, which permits a more precise evaluation of the processing time per item. Their subjects were required to detect a target within an array of items presented too briefly to permit a functional eye movement. The number of array items was varied systematically, and the processing time per item was indexed by the slope of the function relating reaction time $(\mathrm{RT})$ to $n$, the number of items in the array. The results

This research was supported in part by Grant MH 23505 from the National Institute of Mental Health to Henry and Lila Gleitman, and in part by a Sigma XI Grant-in-Aid of Research and a Rackham Faculty Research Grant, both to John Jonides. We wish to thank Ellen Foland and Lauren Birenbaum for their invaluable help in all aspects of the collection of data. We thank Robert M. Steinman for helpful comments, and we are grateful to Jonathan Baron and Howard Egeth for a critical reading of the manuscript. Finally, we thank Charles Eriksen for valuable editorial suggestions. showed that these slopes are much shallower for between-category than within-category search; in fact, between-category search sometimes yields RT functions that are completely independent of $n$ (Egeth, Atkinson, Gilmore, \& Marcus, 1973; Egeth, et al., 1972; Jonides \& Gleitman, 1972). An analogous category-effect has also been obtained in a same-different simultaneous discrimination task (Posner, 1970).

One might suspect that the greater speed of between- as compared to within-category search is simply the result of some featural stimulus differences between target and field items. For example, one would surely expect RT to be independent of $n$ if the target were a red B embedded among several green letters. Jonides and Gleitman (1972) have shown, however, that such a trivializing interpretation cannot account for the category effect obtained with alphanumeric items. When the target " 0 "' was embedded among letters, the RT function was flat if the subjects searched for the digit "zero," but it had a sizable slope if they were told to search for the letter " 0 " (pronounced "oh"). This demonstrates that a category effect can occur even when the physical difference between target and field items is no greater in between-category than in withincategory search.

A featural hypothesis of the category effect is still tenable, the oh-zero phenomenon notwithstanding. Gleitman and Jonides (1976) and Jonides and Gleitman (1972) have suggested that categorization (e.g., deciding whether a given item is a digit) requires less detailed extraction of featural information than does identification (e.g., deciding whether an item is a "4"). According to this "partial processing" hypothesis, the features analyzed 
during between-category search are either fewer in number or are somehow "easier" to extract than are those required for within-category search. This account is in principle not incompatible with the oh-zero effect. To explain this phenomenon one must assume that the item " 0 "' is ambiguous in the sense of containing some features of both the letter and digit categories. One must further assume that some facets of the subject's feature extraction mechanism can be guided by instruction and are thus flexible. Thus, in searching for a zero among letters, one extracts digit-defining features; in searching for an "oh" among letters, one examines items for features that define the letter "oh."

How can this mechanism be investigated? One way might be to search for the actual physical features that distinguish among alphanumeric characters. An alternative approach is to test some implications of the partial processing hypothesis without making any specific commitments on the actual features involved. One such implication is that categorization has a cost: between-category-search should result in comparatively impaired item identification. Gleitman and Jonides (1976) confirmed this prediction for both field and target items. When tested subsequent to a series of visual search trials, withincategory searchers showed some incidental learning of the field items to which they had just been exposed. In contrast, between-category searchers showed no evidence of such incidental learning at all. Using a different experimental technique, an analogous cost of categorization was demonstrated for target items as well. Between-category searchers who were looking for, say, a " 4 " or a " 7 " among letters were given a catch trial on which the stimulus card contained a " 3 "; virtually all of them responded that the specified target was present. This result is in clear accord with the partial processing hypothesis. The subjects noted that there was a digit present without noting what particular digit it was.

Such evidence demonstrates that partial processing has a cost. But how does it confer its benefit, the faster discovery of a target in between- than in within-category search? The hypothesis, again, is that less information (i.e., fewer or more readily processed features) must be extracted to determine, say, that a digit is present. But if partial processing is this and nothing more, then between-category search would yield only the discovery that there is a digit present somewhere in the array of letters. The between-category searcher would not know where, and hence would have no further advantage over the within-category searcher should he be asked to process the target further. This is rather implausible, for everyday experience suggests that, on the contrary, between-category search is a distinct aid in item identification. To identify a cowboy as John Wayne might take a bit of time if there were a dozen other cowboys in the scene; to identify him among a herd of cows would surely be easier. That is, it is more plausible that partial processing (to discover categorial difference) should be preliminary to the more detailed processing required for item identification. If so, it would not only enable the searcher to discover that one of the items is different from the others, but would also allow him to determine which of the items is different. As a result, the different item could be singled out and be subjected to further analysis (i.e., identified).

The present paper describes four experiments that demonstrate that categorial processing can be the first step in a multistage processing sequence. The first experiment shows that between-category searchers take less time than their within-category counterparts even when their task is to identify the target. This demonstrates that the partially processed item is "tagged" for further analysis. Three other experiments suggest that this tagging is based upon spatial location information provided by partial processing: the system first discovers the location of the array item that is categorially different, and it then proceeds to process this item until it has been identified.

\section{EXPERIMENT I}

In the studies of the category effect described thus far, the between-category searcher is only required to report whether a categorially different item is present or absent in the array. Its specific identity need not concern him, for it does not affect his task. If he is asked to look for the targets " 4 " and " 6 " among letters, for instance, he has to search only for a digit, regardless of which. This, in fact, is just what he does, as shown by the catch-trial study described previously (Gleitman \& Jonides, 1976).

The present experiment asks what happens when a between-category searcher is forced to identify the categorially different item. To answer this question, a modified between-category condition (MB) was employed. The subjects looked for digit targets (e.g., 2 and 4 ) among letter field items. The subjects were forced to identify the targets before responding because $25 \%$ of all the trials were catch trials on which a wrong digit (e.g., a "3") was present in the array. The RT functions obtained with this procedure were compared with those found under standard withincategory (W) and between-category (B) conditions.

Given the hypothesis that partial processing singles out the categorially different item which is then further processed, two predictions follow. To begin with, the slopes of the RT functions of conditions B and MB should be identical and should both be substantially smaller than the comparable slope obtained in condition W. Further, conditions B and MB should differ in the intercept of their RT func- 
tions. This follows from the assumption that both $B$ and $M B$ subjects first single out the categorially different target. Once this is accomplished, the B subject's task is finished, but the MB subject must continue processing; he has to identify the digit and he must then compare it to the two digits in his memory which were specified as the targets.

\section{Method}

Subjects. Eleven male and 13 female undergraduates served as subjects. Each was paid for participation in a $30-\mathrm{min}$ experimental session.

General design. Eight subjects each were assigned to three groups, W, B, and MB. Each group had to perform a visual search task. For Group W, the search was within-category. On $50 \%$ of the trials (randomly ordered) there was a letter target among one or more letter field items; on the other $50 \%$ of the trials, there were only letter field items. Groups B and MB were both required to perform a between-category search task, but with a crucial difference. For subjects in Group MB, mere categorization of the target was not enough; they also had to identify it. On $50 \%$ of the trials, both groups received the identical stimulus items: a digit target embedded among one or more letter field items. The procedural difference between Groups B and MB pertained to the trials on which the specified target was not present. For Group B on these trials (50\% of the total), there were only letter field items. For Group MB, the nontarget trials were further subdivided. On half of them (that is, $25 \%$ of all trials), there were only letter field items, precisely as for Group B. On the other half of the nontarget trials (again, $25 \%$ of all trials), there was one digit among one or more letter field items, but this digit was not one of the targets specified for this trial. Thus, for example, an MB subject might be asked to look for a "2" or a "4" on a given trial and would then be presented with a "7" (to which he should not respond).

Stimulus materials. On each trial, two targets were specified (e.g., "press the button if you see either a 3 or a 6"). They were drawn from a total population of eight possible targets. For Groups B and MB, the target population consisted of the digits 2 through 9; for Group W, it consisted of the eight letters A, B, G, L, P, R, S, and Z. Each of these target items was specified equally often, and was equally likely to be specified as the first target or as the second. The field items for all groups were chosen from the set of letters: C, D, E, F, H, J, K, M, N, O, U, V, and Y. Three display sizes $(2,4$, and 6$)$ were used equally often over the 192 test trials.

The stimuli were presented in an Iconix mirror tachistoscope, Model 6137-4. Prior to each trial, the subject was asked to look at a fixation dot on a blank screen $(15.5 \mathrm{~mL})$; he initiated the trial himself by depressing a foot pedal. Half a second later, the stimulus card appeared for $200 \mathrm{msec}$, followed by a masking field made up of pieces of letters and digits. The masking field stayed on for $1 \mathrm{sec}$, after which the fixation dot reappeared and remained for an intertrial interval of about $5 \mathrm{sec}$.

The stimulus items were black Letraset numerals and uppercase letters (Folio Medium, 24-point, $.34^{\circ}$ in height). Both target and field-items were located around the circumference of an imaginary circle whose diameter was $3.4^{\circ}$ and whose center coincided with the position of the fixation dot. The item locations were chosen from among the 12 clock positions of this circle. This procedure is an adaptation of a technique introduced by Eriksen and his colleagues (e.g., Eriksen \& Rohrbaugh, 1970).

There were 96 target cards in all. Each of the eight targets was used 12 times, 4 times for each display size. Each target appeared once in each of the 12 possible locations. The placement of the field items (each of which was used equally often) was governed by one major constraint: one field item had to be placed diametrically opposite to the target. By this arrangement, the maximum angle subtended by the array items was held constant. Apart from this constraint, the locations of the field items were chosen at random from among the remaining loci. For Groups W and B, a matched set of 96 nontarget cards was constructed by substituting a randomly selected field item for the target on each of the target cards. For further details regarding construction of the stimuli, see Egeth et al. (1972) and Jonides and Gleitman (1972).

For Group MB, the 96 target cards were identical to those used for Group B. Of the 96 nontarget cards for this group, one set of 48 was constructed in a manner equivalent to that used for Groups $W$ and $B$. The remaining 48 nontarget cards contained a "wrong" digit among one or more letter field items; these cards were constructed in a manner analogous to the genuine target cards.

Procedure. The subjects were first familiarized with all of the field items and with the population of targets appropriate to their group. They were informed about the randomly varying display sizes and about the fact that one of the two specified targets would be present on $50 \%$ of the trials. Group MB, in addition, was informed that on $25 \%$ of the trials a "wrong" digit would appear. All subjects were told to depress a telegraph key when a target was present and not to respond otherwise.' They were instructed to respond as quickly as possible while maintaining a high level of accuracy. At the start of the session, each subject received 32 practice trials similar to the 192 test trials of his assigned experimental condition. Fourteen subjects were excluded from the analysis because they did not meet an error criterion of $6.3 \%$; they were replaced. Of these, one was in Group B and 13 were in Group $W$. The mean error rates of these excluded subjects were $6.8 \%$ for Group B and $9.2 \%$ for Group W.

\section{Results and Discussion}

Reaction times. All calculations in this and the following experiments reported in this paper exclude RTs above or below 2.5 SD for each subject and each condition. Figure 1 presents mean RTs plotted against display size for all groups. To begin with, we find the usual category effect as reflected by the slope difference of the within-category and the "standard" between-category conditions. The mean slopes of the RT functions (that is, the best fit linear components according to a least squares criterion) were $29.9 \mathrm{msec} /$ item $(\mathrm{SD}=8.0 \mathrm{msec}$ ) and $9.9 \mathrm{msec} /$ item ( $\mathrm{SD}=4.7 \mathrm{msec})$ for Groups W and B, respectively, yielding a $\mathrm{t}$ value $(\mathrm{df}=14)$ of 6.0 , $\mathrm{p}<.001$. The important point is that this categoryeffect was undiminished for the modified betweencategory condition. The mean slope of the RT function generated by Group $\mathrm{MB}$ was $9.2 \mathrm{msec} / \mathrm{item}$ $(\mathrm{SD}=4.8 \mathrm{msec})$. This slope was significantly smaller than that found in Group W $(\mathrm{t}=6.2$, $\mathrm{df}=14$, $\mathrm{p}<.001$ ), and was essentially identical to that obtained in Group $\mathrm{B}(\mathrm{t}=0.3, \mathrm{df}=14, \mathrm{p}>.30)$. These results are in line with our prediction: betweencategory searchers benefit from partial processing even when their task is modified so that they are forced to identify the target. If one had to decide whether a cowboy in a herd of cows was John Wayne or Henry Fonda, it wouldn't matter how many cows were in the herd.

While the RT function of Groups B and MB do not differ in slope, they do differ in their inter- 


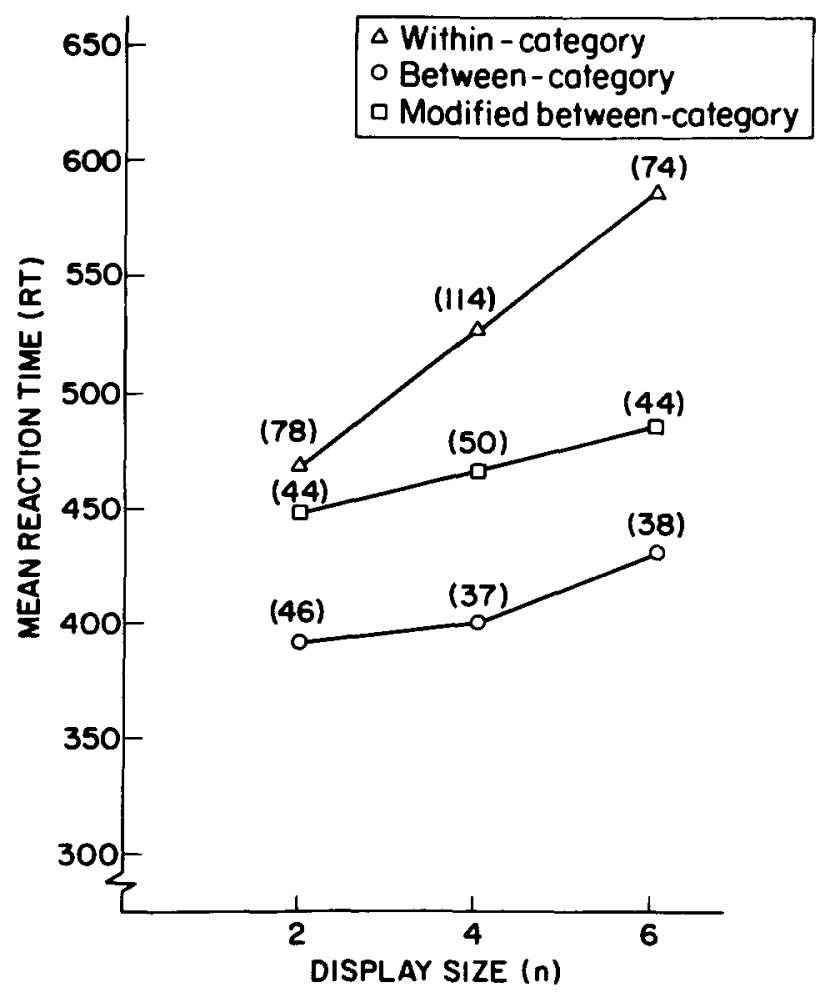

Figure 1. Mean reaction time ( \pm estimates of $o$ ) as a function of display size for within-, and between-, and modified between-category conditions of Experiment I.

cepts. These intercepts are $367 \mathrm{msec}(\mathrm{SD}=49 \mathrm{msec})$ and $429 \mathrm{msec}(\mathrm{SD}=47 \mathrm{msec}$ ) for Groups $\mathrm{B}$ and $\mathrm{MB}$, respectively; $t(14)=2.6, p<.02$. This again is as predicted. The modified between-category condition calls for further processing after the categorially different item has been singled out. This item must then be identified and compared with the targets in memory. Similar reasoning leads to the prediction of a corresponding difference between the intercepts of Groups W and B. The results were in the right direction, but fell short of significance. The intercepts were $407 \mathrm{msec}(\mathrm{SD}=98 \mathrm{msec}$ ) and $367 \mathrm{msec}$ for Groups W and B, respectively, but the $\mathrm{t}$ value $(\mathrm{df}=14)$ was only $1.1, \mathrm{p}>.10$.

Since as many as 13 subjects originally assigned to Group W failed to meet the error criterion, we checked to see how their RT functions compared to those of Group W. The mean slope for the RT functions of these discarded subjects was $37.1 \mathrm{msec} / \mathrm{item}$ $(\mathrm{SD}=13.4 \mathrm{msec})$; the mean intercept was $380 \mathrm{msec}$ $(\mathrm{SD}=65.6 \mathrm{msec})$. If these subjects were trading accuracy for speed, this tradeoff evidently did not diminish the slope-effect characteristic of withincategory search $(\mathrm{t}=1.47, \mathrm{df}=19, \mathrm{p}>.10$, comparing the discarded and the included within-category subjects).

Error rates. The preceding discussion implies that Group W had the most difficult task, Group B had the easiest, and Group MB had a task of inter- mediate difficulty. Group $\mathrm{W}$ had to identify all of the items (or at least half of them, assuming a selfterminating search through the array). Group MB could use a partial processing shortcut to single out the target item which it then had to identify. Group B, finally, had the least demanding job; it only had to find the categorially distinct item, but was not required to identify it. This ordering of task difficulty is supported by the group error rates which were $4.6 \%, 3.0 \%$, and $2.0 \%$ for Groups W, $\mathrm{MB}$, and $\mathrm{B}$, respectively. The difference between the two extreme groups, W and B was highly significant: $\mathrm{t}(14)=3.5, \mathrm{p}<.005$. The intermediate comparisons failed of significance, with $t$ values ( $\mathrm{df}=14$ ) of 1.5 for the difference between Groups $W$ and $M B$, and of 1.2 for the difference between $\mathrm{MB}$ and $\mathrm{B}$.

A methodological issue. One potential problem with the present experiment is a confounding of categorial membership with category condition, since both the $\mathrm{B}$ and $\mathrm{MB}$ conditions had only digits as targets. One might claim that the reduced slopes in these conditions are caused by greater ease in identifying digits. This interpretation is unlikely since several prior studies have shown a category effect when either letters or digits were used as targets (Gleitman \& Jonides, 1976; Jonides \& Gleitman, 1972). In addition; Experiment III of the present paper clearly demonstrates a category effect with letter targets.

\section{EXPERIMENT II}

The preceding experiment has shown that the partial processing which underlies the category-effect not only determines the existence of a categorially different item, but also tags that item so that it can be processed further should the task require this. What is this tag which allows the between-category searcher to single out the distinct item? Perhaps the simplest hypothesis is that it is the item's spatial location in the array. This view is in accord with the reports of many subjects in the between-category condition. They said that the target seemed to "jump out at them," a perceptual isolation effect reminiscent of that described by Neisser's subjects in a search task that required rather simple discriminations (Neisser, 1964). Perhaps the phenomenal experience of "jumping out" is the subjective equivalent of a focusing of attention upon a particular location of the array, caused by the partial processing of a categorial difference. The present experiment is an attempt to provide an objective test of this location hypothesis.

The location hypothesis makes certain predictions. Consider a subject who is presented with one of several targets that may be at one of several locations. Suppose he is sometimes asked what the target 
is and sometimes where the target is. If he is a betweencategory searcher, he should locate the target before he identifies it. This follows from the hypothesis that partial processing first singles out an item in a particular location, and this item is then further processed if need be. We would therefore predict that $L_{B}<I_{B}$, where $L_{B}$ and $I_{B}$ are means RTs for locating and identifying a target, respectively, in a betweencategory condition. Conversely, for a within-category searcher, locating an item cannot possibly be the first step in the search process. His sole way of knowing that a given item is a target is to identify it; he therefore has to know what the target is before he can tell where it is. Under the circumstances, we predict that $\mathrm{L}_{\mathrm{W}}>\mathrm{I}_{\mathrm{W}}$, where $\mathrm{L}_{\mathrm{W}}$ and $\mathrm{I}_{\mathrm{W}}$ are mean RTs for locating and identifying a target, respectively, in a within-category condition.

The situation is somewhat more complicated, however. The predictions, $\mathrm{L}_{\mathrm{B}}<\mathrm{I}_{\mathrm{B}}$ and $\mathrm{L}_{\mathrm{W}}>\mathrm{I}_{\mathrm{W}}$, only follow from the location notion if this is coupled with a further assumption. Specifically, the actual response of telling where the target is must be as easy to perform as the response of telling what it is. But this assumption is undoubtedly false. Suppose the target is a "B." If asked to identify, the subject says "B"; if asked to locate, he says e.g., "left." The second response is certain to be more difficult than the first. The processing sequence by which the subject comes to the mental decision that the target is a " $\mathrm{B}$ " may indeed take longer than that by which he decides that it is to the left. But these two decisions have to be mapped onto two indexing responses. If these responses are not equally difficult, the predicted inequalities may well be masked. That is, there are undoubtedly different stimulus-response compatibilities in the two response conditions that make for longer locational than identificational responses (Broadbent, 1971). This would tend to obscure the predicted inequalities $\mathrm{L}_{B}<\mathrm{I}_{\mathrm{B}}$ and $\mathrm{L}_{\mathrm{W}}>\mathrm{I}_{\mathrm{W}}$.

Under the circumstances, the location hypothesis can make predictions only about relative differences. That is, as described above, the difficulty of giving a location response is presumably greater than that of responding with the name of the item. The prediction of the location hypothesis must therefore be altered to take the comparative difficulty of the locational response into account. This would modify the original predictions. Instead of predicting $\mathrm{L}_{B}<\mathrm{I}_{B}$ and $\mathrm{L}_{\mathrm{W}}>\mathrm{I}_{\mathrm{W}}$, we only predict $\left(\mathrm{L}_{\mathrm{B}}-\mathrm{I}_{\mathrm{B}}\right)<\left(\mathrm{L}_{\mathrm{W}}-\mathrm{I}_{\mathrm{W}}\right)$. That is, the location response will be more difficult than the identification response for both withinand between-category conditions, but this difference will be larger in the within-category condition.

To test this prediction, subjects were presented with one of four possible targets in one of four possible locations. On some trials, they were asked to indicate the target's identity; on others, to indicate its location.

\section{Method}

Subjects. Twelve female undergraduates were paid for participation in a 30-min experimental session.

General design. All subjects were run in a within-subject 2 by 2 factorial design, with categorial condition (within vs. between) and type of response (location vs. identity) as the two factors. The four conditions of the experiment were run in blocked fashion, with order counterbalanced according to a Latin square design. Three subjects were run in each of the four orders of the Latin square.

Stimulus materials. On each trial, the stimulus card contained one target and three field items. The four items were always displayed at the four vertices of an imaginary diamond whose center coincided with the fixation mark and whose diagonals were $3.1^{\circ}$ of visual angle in length. The items were black Letraset numerals and uppercase letters (Futura Demi-bold, 24-point, $.35^{\circ}$ in height). Four letters-D, N, R, and X-served as targets for all conditions. For the within-category conditions, the field items were chosen from among the letters A, B, C, H, L, P, S, and $Z$; for the between-category conditions, the field items were chosen from the set of digits 2 through 9.

Within each of the four experimental conditions, each target was used equally often overall and was placed equally often at each of the four loci. The choice and placement of the field items was randomly determined, except that each field item was used equally often for each of the two response types. In all, there were 128 test trials during the experimental session, 32 for each of the four experimental conditions. In addition, there were 32 practice trials (8 each per condition) constructed according to the same principles as those used for the test cards.

The manner in which the stimuli were presented was identical to that employed in Experiment I except that there was no masking field. Thus, after display offset, the fixation mark simply reappeared.

Procedure. The subjects were first familiarized with the four targets and with all of the field items used in the experiment. They were told that each trial would contain one target and three field items, that the items were placed at the four vertices of an imaginary diamond, that the location of the target was randomly determined, and that for this reason the most efficient strategy was to maintain fixation at the center of the field. They were further told that, on each trial, they had to search for the presence of any one of the four targets, each of which was equally likely to occur. In the two conditions that required an identity response, the subjects had to give the name of the target by speaking into a microphone placed about $2 \mathrm{~cm}$ from their lips. In the two conditions that required a location response, the subjects had to utter one of the four words "up," "down," "left," or "right." RTs were measured from the onset of the display until the subjects' response; this tripped a voice-operated relay that stopped the clock. All subjects were told to respond clearly and crisply, and to respond as quickly as possible while maintaining a high level of accuracy. If the subject slurred a response (which only happened on $.8 \%$ of the trials overall), this was counted as an error. Three subjects failed to meet an error criterion of $9.5 \%$; they were replaced. ${ }^{2}$

All subjects were given 32 practice trials before starting the experimental session. Before each block of 8 practice trials, they were fully informed about the response required (location or identity) and about the kind of stimulus materials that would follow (within- or between-category). This information was also supplied before each of the four blocks of the experimental session.

\section{Results and Discussion}

The mean RTs were 972 and 794 msec (with SDs of 115 and $70 \mathrm{msec}$, respectively) for location and identity responses in the within-category condition. The corresponding mean RTs for the between- 
category condition were 719 and $607 \mathrm{msec}$ (with SDs of 63 and $65 \mathrm{msec}$ ). An analysis of variance showed that both main effects and the interaction between them were highly significant. There was the usual category effect, with longer RTs for within- than for between-category search: $F(1,8)=79.3, p<.001$. There was also a strong effect of response type, with longer RTs when the subject had to locate rather than identify: $F(1,8)=69.6, p<.001$. Of primary concern to the present discussion is the interaction, which reveals that the difference between $L$ and 1 depended upon the categorial condition. As predicted, this difference was greater for withincategory search $(178 \mathrm{msec})$ than for between-category search $(112 \mathrm{msec}): \mathrm{F}(1,8)=17.1, \mathrm{p}<.005$.

The group errors roughly mirror the RTs. The mean error rates were $8.3 \%$ and $4.7 \%$ (with SDs of $6.2 \%$ and $4.1 \%$ ) for location and identity responses, respectively, in the within-category condition. The corresponding figures for the between-category condition were $2.6 \%$ and $.8 \%$ (with SDs of $2.6 \%$ and $1.4 \%$ ). Analysis of variance showed that while both main effects were significant at the .05 level or better, the interaction was not.

\section{EXPERIMENT III}

Experiment II showed that $\left(\mathrm{L}_{B}-\mathrm{I}_{\mathrm{B}}\right)<\left(\mathrm{L}_{W}-\mathrm{I}_{W}\right)$, a result which is consistent with the location hypothesis described above. Partial processing apparently singles out the categorially distinct item by tagging its spatial position.

The obtained inequality of reaction times, however, is evidence for the location hypothesis only if one assumes that the differential response compatibilities of locating and identifying result in some constant increment of time that is added to the location responses of both the within- and between-category conditions. But there is an alternative interpretation of this inequality. We already know that betweencategory search is faster and presumably easier than is within-category search. Suppose the effect of coupling a difficult indexing response onto each of these search tasks does not add the same increment of time to each. This might be the case if, for example, there is a limited total amount of processing capacity which must be shared by all the processes involved in a particular task (see Rumelhart, 1970, for such a model). On this hypothesis, the addition of a difficult location response onto an easy between-category search process might add less to the total RT for this task than for the more difficult withincategory task. The result would be an interaction of just the sort that was actually obtained.

Under the circumstances, some further test of the location hypothesis is clearly desirable. One approach is to find some independent way of manipulating the difficulty of the two indexing responses- for example, by making the location response easier and the identity response more difficult. In actual practice, however, it turns out to be quite cumbersome to equate the difficulty of the two responses. An alternative approach was therefore adopted. For both within- and between-category conditions, subjects were informed of the target's location before it was actually presented. According to the location hypothesis, the only benefit of categorial partial processing is to spatially isolate the distinct item. If so, informing both within- and between-category searchers about the target's location should nullify the difference between these two conditions. To return to John Wayne and Henry Fonda, it shouldn't matter whether they are surrounded by cows or by other cowboys if one already knows where on the range they're supposed to be.

How can the subject be preinformed about the target's location? One can't just tell him that the target will be at, say 9 o'clock, for he will then simply move his eyes to that spot before the trial starts. This, of course, would drastically change the paradigm in which the category effect has been demonstrated. To overcome this problem, the subjects were run according to a procedure adapted from that used by Eriksen and his colleagues (e.g., Colegate, Hoffman, \& Eriksen, 1973; Eriksen \& Collins, 1969; Eriksen \& Hoffman, 1972, 1973). The subject was first presented with the fixation mark. On half of the trials, this fixation mark was followed by a very brief prestimulus cue, a small arrowhead that pointed to one of four possible target locations. Following this, the array items were flashed; letter targets were sometimes embedded among other letters and sometimes among digits, but they were always located in the position precued by the arrow. The other half of the trials were run without the prestimulus cue. Since there is some disagreement about the latency of saccades and about individual differences in these latencies (Komada, Festinger, Phillips, Duckman, \& Young, 1973; Saslow, 1967; White, Eason, \& Bartlett, 1962), the duration of the displays was varied parametrically.

\section{Method}

Subjects. Twelve female undergraduates were paid for participating in a 30-min experimental session.

General design. Four subjects each were assigned to three groups, which differed according to the exposure duration of the stimulus displays $(25,50$, or $75 \mathrm{msec})$. Each group received four blocks of experimental trials whose order was determined by a Latin square principle. The blocks correspond to the four conditions of a 2 by 2 factorial design with categorial condition (within- vs. between-category) and locational information (cued vs. not-cued) as the factors. On all trials, the subject had to indicate which of four targets had appeared. A constant display size of 4 was used throughout.

Stimulus materials. The 176 stimulus cards were constructed according to the same principles as those used in Experiment II, with the same four targets, the same population of field items, and the same diamond-shaped display arrangement. For the 
precued condition, 88 cue cards were constructed. Each of these contained an arrowhead (Letraset \#13275), which was in solid black and whose longest dimension was $23 \mathrm{~min}$ of arc. Its location on the cue card was such that its point was $11 \mathrm{~min}$ from the dead center of the target that was going to appear immediately thereafter.

Prior to the experimental trials, all subjects were given 32 specially constructed practice trials to familiarize them with the use of a locational precue. All 32 cards contained one of the four targets, D, N, R, or X and three dots at the remaining three item loci. The precue was omitted for the first 16 of these practice trials, and included for the last 16 .

Apparatus. All stimulus materials were presented in the mirror tachistoscope previously described. For the two conditions without precue, the order of events was identical to that of Experiment II except that the stimulus display was presented $625 \mathrm{msec}$ after depression of the foot pedal. For the two precue conditions, the precue appropriate to that trial appeared $500 \mathrm{msec}$ after depression of the foot pedal and remained for $125 \mathrm{msec}$. As already mentioned, the duration of the stimulus display varied among the three groups, lasting for 25,50 , or $75 \mathrm{msec}$.

Procedure. The experimental instructions were identical to those used in Experiment II with the following exceptions. First, the subjects were told that they always had to identify the target regardless of its location. They were further told that on two of the trial blocks they would receive a precue pointing to the location of the target. They were also informed that there would be 32 special practice trials, and further, that the first 12 trials of each experimental trial block would be considered as additional practice, and "wouldn't count."

Oniy two subjects failed to meet the error criterion of $9.5 \%$; one was in the 75-msec exposure group, the other in the $25-\mathrm{msec}$ exposure group. Both were replaced.

\section{Results and Discussion}

Mean RTs were calculated on the basis of the last 32 trials of each trial block since the first 12 were considered as practice trials. The means for the within-category condition were $552 \mathrm{msec}$. (SD = $60 \mathrm{msec})$ and $788 \mathrm{msec}(\mathrm{SD}=85 \mathrm{msec})$ for the cued and noncued blocks, respectively. The corresponding means for the between-category condition were $564 \mathrm{msec}(\mathrm{SD}=81 \mathrm{msec})$ and $589 \mathrm{msec}(\mathrm{SD}=$ $65 \mathrm{msec}$ ). These means were pooled for all subjects regardless of the display duration at which they were run since the results were virtually identical in all three groups $(F<1)$.

The mean RTs indicate that the locational precue led to a considerable reduction of RT in withincategory search. But, as predicted, there was no such reliable reduction for the between-category condition. An overall analysis of variance $(\mathrm{df}=1,9$ for all $F$ values) yielded highly significant main effects for categorial condition $(F=76.5, p<.001)$ and for locational precue $(F=66.7, p<.001)$ as well as a highly significant interaction $(F=89.6, p<.001)$. In effect, all differences are due to one condition, uncued within-category search. Individual comparisons showed that the mean RT produced by this condition was significantly higher than those in each of the other three conditions ( $p<.001$ in all cases). Comparisons among the means of the other three conditions showed no significant effect $(p>.05$ in all cases).
The general pattern of these results is mirrored in the error rates. Uncued within-category search led to far more errors than any of the other three conditions; these other three were virtually identical in their error rates. The mean error rates were $9.1 \%$ and $0.5 \%$ for uncued and cued within-category search, respectively (with SDs of $10.0 \%$ and $1.8 \%$ ). The comparable figures for between-category search were $1.6 \%$ and $1.0 \%$ (with SDs of $2.1 \%$ and $1.5 \%$ ). Analysis of variance revealed significant main effects of categorial condition $(F=8.7, p<.02)$ and of locational precue $(F=8.7, p<.02)$, as well as a significant interaction $(F=9.1, p<.02)$.

Since exposure duration proved as an insignificant factor, one can safely conclude that the facilitating effect of precuing was not mediated by eye movements. That is, if the cuing effect were caused by eye movements triggered by the onset of the cuing arrow, this effect should have diminished in magnitude with decreasing total exposure duration (cue plus display). No such diminution occurred. Thus, as Eriksen and his colleagues have shown in similar paradigms (e.g., Colegate, Hoffman, \& Eriksen, 1973; Eriksen \& Collins, 1969; Eriksen \& Rohrbaugh, 1970), the effect of the precue is on the "inner eye," not on the external eye muscles.

The important result for the present purposes is that precuing abolishes the difference between withinand between-category search. The within-category searcher is enormously aided by the precue; the between-category searcher is not helped at all. This result follows directly from the location hypothesis which asserts that categorial partial processing tags the spatial location of the distinct item which can then be processed further. If this is so, the betweencategory searcher already has everything the precue can give him: information about where to attend, that is, where to "look with the inner eye." Under the circumstances, the precue should have no effect. Not so for the within-category searcher. He has no means of partially processing the array to single out the target item; but once he is preinformed about its location, he is on a par with his between-category counterpart.

\section{EXPERIMENT IV}

The results of the preceding experiment appear to support our prediction: within-category search is enormously aided by a locational precue while between-category search benefits not at all. There are, however, a number of possible artifacts that might have contributed to this result:

(1) Since the spatial location of the arrowhead was very close to the place in which the target appeared shortly after, there may have been forward visual masking. This may have had a differential effect on between- and within-category processing. 
(2) As already mentioned, the subjects in the previous experiment were run in a 30 -min session. With such little practice, the subjects may not have been able to take full advantage of the locational precue.

(3) A further problem is posed by the response requirements of the task set in Experiment III. The subjects had to indicate which of four possible targets was present in the display. During the noncued within-category condition. The subject necessarily had to hold all four letters in memory. But he didn't have to do so during the precued within-category condition; he simply called out the letter to which the arrow had pointed. This differential memory load might have been responsible for the faster RTs of the precued within-category condition.

(4) A final concern was with the lack of counterbalancing of target category and category condition since the targets in Experiment III were always letters.

The present experiment was designed to meet all four of these objections.

\section{Method}

Subjects. Two male and two female undergraduates were paid for participation in four 45 -min experimental sessions run on 4 consecutive days.

General design. The experiment followed the general scheme of Experiment III. There were four major changes. (1) To rule out the possibility of an artifact due to visual masking, the arrowhead was presented in the dead center of the display, pointing to the target location $1.3^{\circ}$ away from its tip. (2) All subjects were run for four sessions of 240 trials each to provide ample opportunity for practice. (3) The experimental task was to detect the presence of one of several targets. On $50 \%$ of the trials, no target was present. Under the circumstances, the subjects were compelled to keep the targets in memory during both cued and noncued within-category conditions. (4) The targets were always digits, the field items either digits or letters.

Stimulus materials. There were four blocks of 48 test trials per session. Each block correspond to one of the four experimental conditions-cued and uncued within-category, cued and uncued between-category. The targets for all four blocks were the digits 3,4 , and 7 ; the field items were drawn either from the set $2,5,6,8$, and 9, or from the set G, K,P, S, and Z. As in Experiment 11 and III, each card contained four items that were placed at the vertices of an imaginary diamond whose diagonal was $3.1^{\circ}$. On half of the trials in each block (randomly ordered), one of the items was a target; on the other half, no target appeared. Each target was used equally often and was located equally often in each of the four loci. The field items were selected at random from their appropriate set with the constraint that each appear equally often during each trial block. Immediately preceding each trial block were 12 practice trials, 6 with a target present and 6 without a target. The stimulus cards for these practice trials were constructed according to the same principles as the test cards.

For the precued conditions, cue cards were constructed that contained the same arrowhead used in Experiment III. Its location, however, was always in the center of the diamond pointing towards the place where the target was to appear in the event that there was a target. When no target was present, the arrowhead (again in the center of the diamond) pointed equally often to each of the four vertices.

Procedure. On each trial, the order of events was as follows. The subject fixated at a point in the center of the display. $\mathrm{He}$ initiated the trial by depressing a foot switch. When he did so in the cued conditions, the fixation field was replaced $500 \mathrm{msec}$ later by a cue card containing the arrowhead. This remained in view for $125 \mathrm{msec}$. After this, the stimulus display was presented for $25 \mathrm{msec}$ and was then replaced by the fixation field. The sequence of events was identical in the uncued conditions except that instead of an arrowhead the subject was presented with a larger fixation point.

The subjects were instructed to respond with a keypress when one of the three specified targets was present and not otherwise. For the precued conditions, they were informed that the arrowhead always pointed to a target if one was present. As in Experiment III, they were informed of the nature of the four experimental conditions and of the practice trials. As always, they were asked to respond as quickly and as accurately as they could.

The four trial blocks were presented in an order counterbalanced according to a Latin square over subjects and days. Naturally, within each trial block, the order of target and nontarget cards was randomized. All further details of apparatus, stimulus materials and procedure were as in Experiment III.

No subjects were excluded due to high error rate.

\section{Results and Discussion}

Reaction times. The results are presented in Table 1 which displays mean RTs and SDs for the four experimental conditions on each day. As the table shows, the pattern of results is substantially identical to that obtained in Experiment III. The effect of precuing is present only in the within-category condition. This is indicated by a reliable interaction between category condition and the presence or absence of the precue ( $F=14.3, \mathrm{df}=1,3, \mathrm{p}<.05$ ). Comparisons among the individual means (summed over days) indicate that the only reliable differences are those between the uncued within-category condition and all three others (all three $p$ values were less than .05). The three other conditions did not differ significantly from one another (all $p$ values were greater than .05).

The pattern of data in Table 1 suggests the presence of a practice effect; but analysis of variance revealed that the decline in reaction times over days was not reliable $(F=3.82, \mathrm{df}=1,9, \mathrm{p}>.05)$. In fact, this effect still fails to reach significance when only Days 1 and 4 are considered in the analysis $(F=$

Table 1

Mean RTs (with Standard Deviations in Parentheses) of the Four Experimental Conditions of Experiment IV for Each Day of Practice

\begin{tabular}{|c|c|c|c|c|c|}
\hline & \multicolumn{2}{|c|}{ Within-Category } & \multicolumn{2}{|c|}{ Between-Category } & \multirow[b]{2}{*}{ Mean } \\
\hline & Cued & Uncued & Cued & Uncued & \\
\hline Day 1 & $\begin{array}{c}478 \\
(115)\end{array}$ & $\begin{array}{c}67.0 \\
(258)\end{array}$ & $\begin{array}{c}465 \\
(105)\end{array}$ & $\begin{array}{c}482 \\
(115)\end{array}$ & 524 \\
\hline Day 2 & $\begin{array}{c}402 \\
(42)\end{array}$ & $\begin{array}{c}486 \\
(62)\end{array}$ & $\begin{array}{c}387 \\
(40)\end{array}$ & $\begin{array}{c}396 \\
(40)\end{array}$ & 418 \\
\hline Day 3 & $\begin{array}{c}375 \\
(27)\end{array}$ & $\begin{array}{c}438 \\
(26)\end{array}$ & $\begin{array}{c}362 \\
(25)\end{array}$ & $\begin{array}{l}381 \\
(32)\end{array}$ & 389 \\
\hline Day 4 & $\begin{array}{c}382 \\
(32)\end{array}$ & $\begin{array}{c}434 \\
(63)\end{array}$ & $\begin{array}{c}367 \\
(35)\end{array}$ & $\begin{array}{c}371 \\
(\quad 30)\end{array}$ & 389 \\
\hline Mean & 409 & 507 & 395 & 408 & \\
\hline
\end{tabular}


3.78, $\mathrm{df}=1,3, \mathrm{p}>.10$ ). Likewise, the interaction between cue presence and days, and the triple interaction of Cue Presence by Category Condition by Days fails to reach significance, both when all 4 days are included in the analysis $(F=3.39$, $\mathrm{df}=3,9$, $\mathrm{p}>.05$, and $F=3.13$, df $=3,9, \mathrm{p}>.05$ ) and when only the first and last days are included $(F=5.02$, $\mathrm{df}=1,3, \mathrm{p}>.10$, and $\mathrm{F}=4.08$, df $=1,3, \mathrm{p}>.10$ ). Although the main effects and interactions of practice fail to reach significance (in most cases, marginally so), it does appear that there is some decline in the advantage conferred by the cue in the within-category condition over days. This is due to the fact that the RTs of the noncued within-category blocks decline more rapidly than do those of the cued blocks. One possible interpretation of this marginal effect is that with practice subjects begin to learn the features which distinguish these particular targets from the field items of the within-category condition. (The targets and field items were the same throughout.) The reason why the benefit of practice is less pronounced for the between-category condition is presumably that the subjects are sensitive to the relevant features from the very outset, with little room left for further improvement. In effect, the processing strategy used in the within-category condition may thus be transformed until it resembles the one utilized in the between-category task.

Error rates. The error rates were quite low. They tended to be lower when there was a precue. In the between-category condition, the mean error rate was $1.0 \%$ when there was a cue and $3.1 \%$ when there was not. The corresponding figures for the withincategory blocks were $1.0 \%$ and $4.4 \%$. There was also a tendency for errors to decline as practice progressed. The mean error rates for the 4 days were $3.7 \%, 2.5 \%, 1.7 \%$, and $1.8 \%$.

Conclusions. It appears that none of the four artifactual interpretations of the results of Experiment III is tenable. The differential effect of the precue was found in the present experiment even though the possibility of visual masking was eliminated, even though adequate practice was provided, even though the memory load for the two within-category conditions was equalized, and even though the category of the target items was changed. Under the circumstances, the partial processing hypothesis seems to provide a plausible account of the data.

\section{GENERAL DISCUSSION}

The four present experiments, taken together, provide support for a partial processing hypothesis of the category effect in visual search. According to this hypothesis, categorization (e.g., deciding whether an array item is a digit) requires less detailed processing than does identification (e.g., deciding whether an item is a 4), thus resulting in less examination time for each item presented and hence a faster reaction time for between- than for within-category search. Gleitman and Jonides (1976) demonstrated that this partial processing has a cost: less information is registered and/or retained about both targets and field items during between- than during withincategory search. The present experiments provide evidence on the benefit of partial processing. It allows the subject to locate the target without identifying all the distractor items first. Once located, the target can then be subjected to further analysis if necessary.

\section{REFERENCES}

Brand, J. Classification without identification in visual search. Quarterly Journal of Experimental Psychology, 1971, 23, 178-186.

Brondbent, D. E. Decision and stress. New York: Academic Press, 1971.

Colegate, R. L., Hoffman, J. E., \& Eriksen, C. W. Selective encoding from multielement visual displays. Perception \& Psychophysics, 1973, 14, 217-224.

Egeth, H., Atrinson, J., Gilmore, G., \& Marcus, N. Factors affecting processing mode in visual search. Perception \& Psychophysics, 1973, 13, 394-402.

Egeth, H., Jonimes, J., \& Wall, S. Parallel processing of multielement displays. Cognitive Psychology, 1972, 3, 674-698.

Egeth, H. E., Marcus, N., \& Bevan, W. Target-set and response-set interaction: Implications for models of human information processing. Science, 1972, 176, 1447-1448.

ERIKsen, C. W., \& Collins, J. F. Temporal course of selective attention. Journal of Experimental Psychology, 1969, 80, 254-261.

ERIKSEN, C. W., \& Hoffman, J. E. Some characteristics of selective attention in visual perception determined by vocal reaction time. Perception \& Psychophysics, 1972, 11, 169-171.

Eriksen, C. W., \& Hoffman, J. E. The extent of processing of noise elements during selective encoding from visual displays. Perception \& Psychophysics, 1973, 14, 155-160.

Eriksen, C. W., \& Rohrbaugh, J. Some factors determining efficiency of selective attention. American Journal of Psychology, 1970, 83, 330-342.

Gleitman, H., \& Jonides, J. The cost of categorization in visual search: Incomplete processing of target and field items. Perception \& Psychophysics, 1976, 20, 281-288.

INGLING, N. W. Categorization: A mechanism for rapid information processing. Journal of Experimental Psychology, 1972, 94, 239-243.

Jonides, J., \& Gleitman, H. A conceptual category effect in visual search: $O$ as letter or as digit. Perception \& Psychophysics, 1972, 12, 457-460.

Komoda, M. K., Festinger, L., Phillips, L. J., Duckman, R. H., \& Young, R. A. Some observations concerning saccadic eye movements. Vision Research, 1973, 13, 1009-1020.

NeISSER, U. Decision-time without reaction-time: Experiments in visual scanning. American Journal of Psychology, 1963, 76, 376-385.

NeIsSER, U. Visual search. Scientific American, 1964, 210 , 94-102.

Posner, M. I. On the relationship between letter names and superordinate categories. Quarterly Joumal of Experimental Psychology, 1970, 22, 279-287.

Rumelhart, D. E. A multicomponent theory of perception of briefly exposed visual displays. Joumal of Mathematical Psychology, 1970, 7, 191-218. 
SAsLOW. M. G. Latency for saccadic eye movement. Journal of the Optical Society of America. 1967, 57, 1030-1033.

Whte, C. T., EAson, R. G., \& BARTLETt, N. R. Latency and duration of eye movements in the horizontal plane. Journal of the Optical Society of America, 1962, 52, 210-213.

\section{NOTES}

1. There are two reasons for using this "go, no-go" procedure (in which the subject only gives a "present" response) in preference to a two-choice task (in which subject must choose between a "present" and an "absent" response). In the first place, some of our pilot studies showed that RT variance is substantially lower in the "go, no-go" situation. Secondly, a study by Egeth, Marcus, and Bevan (1972) indicated that the slopes of the RT functions obtained in a memory search task are lower in a oneresponse than a two-response task. This suggests that the addition of the response choice interacts with some of the processing stages in which we are here interested. We therefore opted for a task that called for a minimum of output effort on the subject's part.

2. A different error criterion was used in this study than in Experiment I because the radically different experimental procedure proved to be more difficult. In Experiment I, the subject only had to indicate whether a target was present; in the present study he had to identify or locate one of four targets that was invariably present.

(Received for publication March 31, 1976; revision accepted August 4, 1976.) 